\title{
Injury patterns of South African international cricket players over a two-season period
}

\author{
Richard A Stretch ${ }^{1}$ (DPhil) \\ Ryan P Raffan ${ }^{2}$ (BA, HMS Hons) \\ ${ }^{1}$ Sport Bureau, Nelson Mandela Metropolitan University, Port Elizabeth, South Africa \\ ${ }^{2}$ Department of Human Movement Science and Sport Management, Nelson Mandela Metropolitan University, Port Elizabeth, South Africa
}

\begin{abstract}
Objective. The aim of the study was to determine the incidence and nature of injury patterns of South African international cricket players.

Methods. A questionnaire was completed for each cricketer who presented with an injury during the $2004-2005\left(S_{1}\right)$ and 2005 - $2006\left(S_{2}\right)$ cricket seasons to determine the anatomical site, month, diagnosis and mechanism of injury.

Results. The results showed that 113 injuries were sustained, with a match exposure time of 1906 hours for one-day internationals (ODIs) and 5070 hours for test matches. The injury prevalence was $4 \%$ per match, while the incidence of injury was 90 injuries per 10000 hours of matches. Injuries occurred mostly to the lower limbs, back and trunk, upper limbs and head and neck. The injuries occurred primarily during test matches (43\%), practices $(20 \%)$ and practices and matches $(19 \%)$. Acute injuries comprised $87 \%$ of the injuries. The major injuries during $\mathrm{S}_{1}$ were haematomas $(20 \%)$, muscle strains $(14 \%)$ and other trauma $(20 \%)$, while during $S_{2}$ the injuries were primarily muscle strains $(16 \%)$, other trauma (32\%), tendinopathy $(10 \%)$ and acute sprains $(12 \%)$. The primary mechanisms of injury occurred when bowling $(67 \%)$, on impact by the ball (batting $-65 \%$, fielding $26 \%)$ and when sliding for the ball (19\%).

Conclusion. The study provided prospective injury incidence and prevalence data for South African cricketers playing at international level over a two-season period, high-lighting the increased injury prevalence for away matches and an increased match injury incidence for test and ODI matches possibly as a result of increased match exposure time.
\end{abstract}

\section{CORRESPONDENCE:}

Dr Richard Stretch

Nelson Mandela Metropolitan University

PO Box 77000

Port Elizabeth

6031

E-mail: richard.stretch@nmmu.ac.za

\section{Introduction}

Long-term injury surveillance has been carried out in Australia, South Africa and England with the view to identifying injury patterns. ${ }^{1-3}$ Data of injuries to Australian state and national cricketers were collected retrospectively for the first three seasons (1995 - 1996 season - 1997 - 1998 season) and then prospectively for the next six seasons (1999 - 2000 season $-2004-2005$ season). ${ }^{3}$ Of the 886 injuries recorded, $92 \%$ were new injuries, $8 \%$ were recurrent injuries and $52 \%$ occurred during major matches. The injuries were mainly sustained while bowling (45\%), with lower limb injuries accounting for $49 \%$ of the injuries. The mean incidence of injuries during matches for the season (injuries/10 000 player hours) was reported for domestic one-day (38.5), first-class (27.3), one-day international (ODI) (59.8) and test (31.4) matches. Fast bowlers missed about $16 \%$ of potential playing time because of injury, while other players missed less than $5 \%$.

The study in South Africa ${ }^{2}$ prospectively recorded 1606 injuries in 783 national and provincial cricketers over a six-season period from 1998/1999 to 2003/2004. More injuries occurred during firstclass matches $(32 \%)$, with limited-over matches $(26 \%)$ and practices and training $(27 \%)$ resulting in a similar number of injuries. Fifteen per cent of the injuries accumulated gradually during the season. The majority of injuries were classified as acute injuries (65\%), with chronic (23\%) and acute-on-chronic (12\%) injuries making up the balance. First-time injuries accounted for $65 \%$, with the balance of injuries from the previous season (22\%) and recurring again during the same season (13\%). Bowling (40\%) accounted for the majority of the injuries, with $55 \%$ of these being lower limb injuries and $33 \%$ back and trunk injuries. Of the 39 stress fractures, $79 \%$ occurred in bowlers. The primary activity associated with injury was the delivery and follow-through of the fast bowler (25\%), running, diving, catching and throwing the ball when fielding (23\%) and overuse (17\%). Other activities included various batting situations, such as being struck while batting $(7 \%)$, running between the wickets $(4 \%)$, batting for long periods at a time (4\%), training specifically for cricket $(4 \%)$ and participating in various other sports $(3 \%)$.

A retrospective study by Leary and White ${ }^{1}$ on 54 cricketers who had played for the same county first team in England between 1985 and 1995 reported 990 injuries, indicating an injury exposure of 17247 days played and an injury incidence rate of 57.4 injuries per 1000 days played. ${ }^{1}$ Most injuries were sustained early in the season, with bowlers most susceptible to injury (70.1 injuries per 1000 days), followed by the all-rounders, batsmen and wicketkeepers with 55.0, 49.4 and 47.3 injuries per 1000 days, respectively. Most injuries occurred to the lower limbs (45\%), with muscle/tendon strains, contusions/haematomas, and ligament/joint sprains the most common injuries. The most vulnerable sites for injury were the thigh and calf $(25 \%)$, fingers $(14 \%)$ and lumbar spine $(11 \%)$. 
The first study to use the internationally recognised surveillance method ${ }^{4}$ reported that 162 domestic and 33 international West Indian cricketers sustained 50 injuries. Most injuries were sustained in test and first-class matches (40\%), with a further $28 \%$ sustained during one-day matches. The injury incidence for test and ODI matches was 48.7 and 40.6 injuries per 10000 player-hours, respectively. For domestic first-class and limited overs matches it was 13.9 and 25.4 injuries per 10000 player-hours, respectively. The injury prevalence for test $(11.3 \%)$ and ODI (8.1\%) matches was lower for home matches than away matches. Bowlers (46\%) and batsmen $(40 \%)$ were at the greatest risk of injury, with muscles $(26 \%)$ and ligament (12\%) injuries, stress fractures (12\%) and fractures $(10 \%)$ the most common injuries. Most of the injuries were new $(80 \%)$, with $10 \%$ recurrent injuries from the previous season and $10 \%$ recurring again during the same season.

All these injury surveillance studies, with the exception of the study on West Indian cricketers, ${ }^{4}$ were carried out prior to the international acceptance of the publication of the consensus paper regarding injury definitions, methods of calculating injury rates and reporting of injuries. ${ }^{2}$ Therefore, the aim of this study was to use the internationally agreed methods for injury surveillance to investigate the seasonal incidence and nature of injuries sustained by South African cricketers to further understand and identify injury patterns, risk factors and other possible factors associated with these injuries.

\section{Methods}

During the $2004-2005\left(S_{1}\right)$ and $2005-2006\left(S_{2}\right)$ cricket seasons, test and ODI matches played by the South African team were monitored prospectively. The data collection and reporting have been done according to the guidelines from the consensus paper developed to allow meaningful comparisons to be made with other international studies. ${ }^{5}$ The physiotherapists working with the teams were required to complete a questionnaire for all cricketers who presented with an injury. The questionnaire was designed to obtain the following information: (i) biographical data; (ii) month of injury during the season; (iii) activity and time of onset of injury; (iv) whether it was a first-time injury or recurrent injury from the previous or current season; $(v)$ chronicity of the injury; (vi) whether the injury had recurred again during the season; (vii) $\mathrm{OSICS}^{6}$ injury classification code; (viii) diagnosis; and (ix) mechanism of injury. Further, in order to determine the player exposure it was necessary to collect information of the player's participation in each match, reasons for non-participation in a match and duration of the match. ${ }^{2}$

For the purpose of this research, an injury was defined as any injury or other medical condition that either: (i) prevents a player from being fully available for selection for a major match; or (ii) during a major match, causes a player to be unable to bat, bowl or keep wicket when required by either the rules or the team's captain. ${ }^{5}$ Acute injuries were those of rapid onset, chronic injuries involved prolonged or extended onset, while acute-on-chronic injuries were increased symptoms of a chronic injury, but were brought about by movements causing rapid onset.

The time in the season when the injury occurred was recorded. Off-season was defined as that part of the season when no specific cricket practice or training was performed. Pre-season was that part of the season when specific cricket practice and training was undertaken before the commencement of matches. Season was defined as that part of the season where matches were played and included international tours. ${ }^{5}$
Injury incidence refers to the number of injuries occurring during the season, while injury prevalence is the average percentage of players who are not available for selection for a match. ${ }^{5}$

One of the limitations of this study was that it does not include the few 20/20 over competitions and the Afro-Asian Cup competitions during this period. Further, the effect of any South African players in the domestic competition was not included here as it has been included in a study on provincial players over the similar period. ${ }^{7}$

The BMDP Statistical Software Package (BMDP, 1993, Los Angeles, BMDP Statistical Software Inc.) was used to compute descriptive statistics. The chi-square test of independence was used to determine whether injury prevalence is related to home and away status.

\section{Results}

One hundred and thirteen injuries were recorded by 36 South African players over the two-season period. The injuries were evenly spread across both seasons $\left(S_{1}=56\right.$ and $\left.S_{2}=57\right)$ and resulted in 39 matches being missed by players. The number of matches played from $S_{1}$ (37) to $S_{2}(33)$, regardless of format or venue, remained fairly consistent (Table I).

TABLE I. Number of matches played and missed

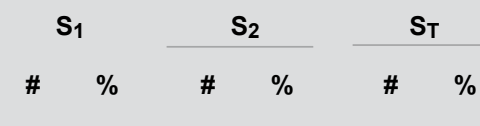

Matches played (\#)

\begin{tabular}{|c|c|c|c|c|c|c|c|}
\hline \multirow[t]{3}{*}{ ODI } & Home \& away & 22 & 100 & 22 & 100 & 44 & 100 \\
\hline & Home & 12 & 55 & 10 & 46 & 22 & 50 \\
\hline & Away & 10 & 46 & 12 & 55 & 22 & 50 \\
\hline \multirow[t]{3}{*}{ Test } & Home \& away & 15 & 100 & 11 & 100 & 26 & 100 \\
\hline & Home & 7 & 47 & 6 & 55 & 13 & 50 \\
\hline & Away & 8 & 53 & 5 & 46 & 13 & 50 \\
\hline \multirow[t]{3}{*}{ Total } & Home \& away & 37 & 100 & 33 & 100 & 70 & 100 \\
\hline & Home & 19 & 51 & 16 & 49 & 35 & 50 \\
\hline & Away & 18 & 49 & 17 & 52 & 35 & 50 \\
\hline \multicolumn{2}{|c|}{ Matches missed (\#) } & 17 & 44 & 22 & 56 & 39 & 100 \\
\hline \multicolumn{2}{|c|}{ Injuries (\#) } & 56 & 50 & 57 & 50 & 113 & 100 \\
\hline \multicolumn{8}{|c|}{$S_{1} \quad 2004-2005$ season. } \\
\hline \multicolumn{8}{|c|}{ S2 2005 - 2006 season. } \\
\hline \multicolumn{8}{|c|}{ ST $2004-2005$ and 2005} \\
\hline
\end{tabular}

The majority of the injuries were first-time $(77 \%)$ and acute $(86 \%)$ injuries in $\mathrm{S}_{1}$, with similar results found in $\mathrm{S}_{2}(75 \%$ and $88 \%$, respectively). The number of recurring injuries from the previous season increased slightly from $S_{1}(9 \%)$ to $S_{2}(11 \%)$ and was 
The major injury categories in $\mathrm{S}_{1}$ were haematomas $(20 \%)$, other trauma $(20 \%)$ and muscle strains $(14 \%)$. However, the results were more evenly spread for $S_{2}$, with the major injury categories being muscle strains $(16 \%)$, acute sprains $(12 \%)$ and tendinopathies $(10 \%)$. A large increase in other trauma was reported from $S_{1}(20 \%)$ to $\mathrm{S}_{2}(32 \%)$ (Table III).

In $\mathrm{S}_{1}$ the majority of injuries occurred while bowling (34\%), fielding (25\%) and batting (23\%). In $\mathrm{S}_{2}$ the injuries were distributed more evenly among fielding (23\%), batting (23\%) and bowling (19\%). The mechanisms for injury were mainly impact when batting $(N=17)$ and fielding $(N=7)$, bowling and bowling for long periods $(N=20)$ and illness $(N=25)$ (Table IV). More injuries occurred during the first half of the season (October - December) than the second half (January - March) (Table V).

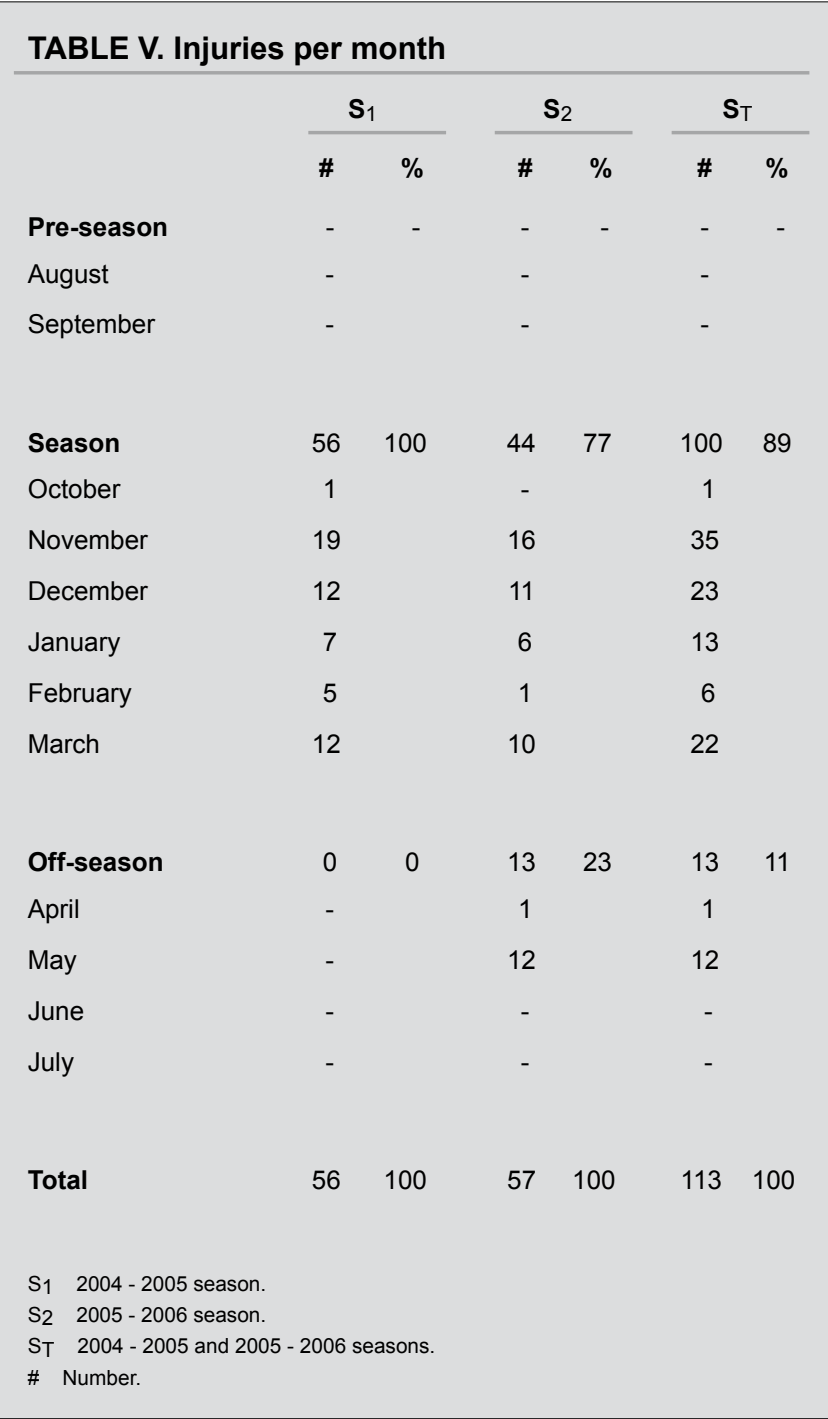

The match exposure time of ODI and test matches was 1906 $\mathrm{h}$ and $5070 \mathrm{~h}$, respectively, with a total match exposure time of $6976 \mathrm{~h}$ (Table VI). The ODI injury prevalence was higher for away matches $(5 \%)$ than home matches $(2 \%)$. Similar results were found for the test injury prevalence, with away matches $(6 \%)$ producing more missed matches than home matches $(2 \%)$. The total injury prevalence was higher for away matches $(6 \%)$ than home matches $(2 \%)$, showing a moderate practical significant difference (chi-square

\section{TABLE VI. Exposure time, injury prevalence and} incidence

\section{Exposure time (h)}

OD

Away

Total

$\mathbf{S}_{1} \mathbf{s}_{2} \mathbf{S}_{\mathrm{T}}$

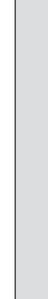

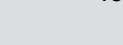
Test Home
Away
Total

$\begin{array}{lll}1560 & 975 & 2535\end{array}$

$2925 \quad 2145 \quad 5070$

Total Home

Away

$\begin{array}{lll}1885 & 1603 & 3488\end{array}$

Total

$\begin{array}{lll}1993 & 1495 & 3488\end{array}$

$3878 \quad 3098 \quad 6976$

Injury prevalence (\% per match)

$\begin{array}{llll}\text { ODI Home \& away } & 2.5 & 4.5 & 3.5 \\ \text { Home } & 2.2 & 1.3 & 1.8 \\ \text { Away } & 2.9 & 7.2 & 5.2\end{array}$

Test Home \& away

Home

Away

$\begin{array}{lll}4.2 & 4.1 & 4.2 \\ 2.2 & 2.2 & 2.2 \\ 6.0 & 6.4 & 6.2\end{array}$

Total Home \& away

$\begin{array}{lll}3.2 & 4.4 & 3.8 \\ 2.2 & 1.6 & 2.0 \\ 4.3 & 7.0 & 5.6\end{array}$

Injury incidence (injuries/10 $000 \mathrm{~h}$ )

$\begin{array}{lccc}\text { ODI } & 53 & 105 & 79 \\ \text { Test } & 101 & 84 & 95 \\ \text { Total } & 90 & 90 & 90\end{array}$

S1 $2004-2005$ season.

S2 2005 - 2006 season.

ST $2004-2005$ and 2005 - 2006 seasons.

(1) $=5.13, p=0.023, V=0.07$, and increased slightly from $S_{1}(3 \%)$ to $\mathrm{S}_{2}(4 \%)$. The injury prevalence was higher in test $(4.2 \%)$ than ODI $(3.5 \%)$ in both home (test: $2.2 \%$ and ODI: $1.8 \%$ ) and away (test: $6.2 \%$ and ODI: $5.2 \%$ ) matches. The match injury incidence of ODI and test matches was 79 and 95 injuries $/ 10000 \mathrm{~h}$, respectively, with a total match injury incidence of 90 (Table VI). No home and away injury incidence could be calculated.

\section{Discussion}

The first important finding was that the injury prevalence was greater in test $(4.2 \%)$ than ODI $(3.5 \%)$ matches. When compared with the West Indian and Australian study, the South African injury prevalence was less than in the West Indian and Australian test (11.3\% and $7.0 \%$, respectively) and ODI $(8.1 \%$ and $10.0 \%$, respectively) 
matches. A possible explanation for this is that the West Indian and Australian studies were conducted over only one season, with the possibility of one serious injury requiring surgery and a long-term layoff having a greater effect on the injury prevalence.

The second important finding was that the South African match injury incidence for test $(95 / 10000 \mathrm{~h})$ and ODI $(79 / 10000 \mathrm{~h})$ matches was significantly higher than that of the West Indian and Australian test (48.7 and 23.1 injuries/10 $000 \mathrm{~h}$, respectively) and ODI (40.6 and 38.5 injuries $/ 10000 \mathrm{~h}$, respectively) injury incidence. ${ }^{4}$ In the current study no practice or fitness exposure time was recorded for the South African cricketers, which would greatly influence injury incidence as seen by the South African provincial cricketers. ${ }^{8}$ Further, the South African cricketers had more match exposure time compared with that of the West Indian and Australian studies.

A large number of injuries were first-time injuries of an acute nature, which included impact injuries, particularly when batting, resulting in haematomas and other trauma injuries. However, there was an increase in recurring injuries from the previous season, which was accompanied by an increase in acute-on-chronic injuries, with the majority of the injuries being muscle strains, tendinopathies and acute sprains. The abovementioned could have been the result of the players returning to play without being fully rehabilitated and the nature of the injury sustained.

When playing international cricket, test matches are generally scheduled to be played first in the series before the ODIs, which could explain the increased number of injuries during the early part of the season regardless of home and away matches. However, the increased number of injuries towards the end of the season could be due to the South African end-of-year tours. During the longer version of the game the players tend to be relatively inactive for long periods of time before rapidly moving after the ball when fielding. Bowlers may be required to bowl multiple spells, sometimes accumulating more than 20 overs in a day compared with four - ten over spells in limited over cricket. This could have resulted in the large number of injuries that occurred during fielding and bowling, particularly during test cricket. Similar results were found with the South African provincial players. $^{7}$

The primary mechanisms of injury were bowling, sliding for and impact by the ball when fielding. Similar results were found where many of the West Indian injuries were muscle strains caused by running after and picking up the ball and injuries to young fast bowlers. ${ }^{3}$ These activities all require some kind of stop-start movement and/or change in direction of the whole body requiring strength, agility and flexibility. In sports involving bouncing and jumping activities, with a high intensity of a stretch-shortening cycle, a stretching programme significantly influenced the viscosity of the tendons, making them more compliant, and stretching may be beneficial for injury prevention. ${ }^{7}$

For both ODI and test matches the injury prevalence showed a practical significant greater difference for away than home matches, which was similar to the West Indian study. ${ }^{4}$ The possible reason could be multifactorial and could include factors such as unfamiliar climate and underfoot conditions, different food and beverage intake, amount of time before receiving medical treatment, particularly in the case of illnesses such as upper-throat respiratory tract infections, gastrointestinal infection and infection. A second report on West Indian cricket has shown a decrease in the number of away injuries over the past five years as a result of a physiotherapist and a structured medical panel overseeing the management of injuries when on tour, ${ }^{9}$ which appears now to be standard practice with all the touring teams of the major cricket- playing nations.

\section{Conclusion}

Injury surveillance is the fundamental process behind successful injury prevention and should be carried out on an on-going long-term basis using the internationally accepted injury surveillance method for the reporting of injuries at all levels of South African cricket. The study provided prospective injury incidence and prevalence data for South African cricketers playing at international level over a two-season period, highlighting the increased injury prevalence for away matches and an increased match injury incidence for test and ODI matches, possibly as a result of increased match exposure time.

\section{REFERENCES}

1. Leary T, White J. Acute injury incidence in professional county cricket players (1985-1995). Br J Sports Med 2000;34:145-147.

2. Stretch RA, Venter DJL. Cricket injuries - a longitudinal study of the nature of injuries to South African cricketers. SA J Sports Med 2005;17(3):4-9.

3. Orchard J, James T, Alcott E. Injuries in Australian cricket at first class level 1995/1996 to 2000/2001. Br J Sports Med 2002;36:270-275

4. Mansingh A, Harper L, Headley S, King-Mowatt J, Mansingh G. Injuries in West Indian cricket 2003-2004. Br J Sports Med 2006;40:119-123.

5. Orchard J, Newman D, Stretch R, Frost W, Mansingh A, Leipus A Methods for injury surveillance in international cricket. J Sc Med Sport 2005;8(1):1-14.

6. Orchard J. Orchard sports injuries classification system (OSICS). In: Bloomfield J, Ficker P, Fitch K, eds. Science and Medicine in Sport. 2nd ed. Melbourne: Blackwell, 1995:674-681.

7. Stretch R, Raffan RP, Allan N. Injury patterns of South African provincial cricket players over a two season period. SA J Sports Med 2009;21(4):151-155.

8. Witvrouw E, Mahieu N, Danneels L, McNair P. Stretching and injury prevention: An obscure relationship. J Sports Med 2004;34(7):443-449.

9. Mansingh A. Injuries in West Indies cricket: has there been a change in the last five years? 4th World Congress on Science and Medicine in Cricket, Chandigarh, India 2011. 